\title{
DEVELOPMENT OF A SEMI-DISTRIBUTED HYDROLOGICAL MODEL FOR GLACIATED PUNATSHANGCHU BASIN IN BHUTAN
}

\author{
Vasker Sharma $^{1 *}$, Jessica Jordan², Pedro Manso ${ }^{3}$, Giovanni De Cesare ${ }^{4}$ \\ Department of Civil Engineering and Surveying, Jigme Namgyel Engineering College, Dewathang ${ }^{1}$ \\ Ecole Polytechnique Fédérale de Lausanne, Platform of hydraulic construction (PL-LCH), Switzerland 2,3,4 \\ vaskersharma.jnec@rub.edu.bt ${ }^{1}$,zordanjessica@gmail.com², pedro.manso@epfl.ch ${ }^{3}$, giovanni.decesare@epfl.ch 4
}

\begin{abstract}
Hydropower plays a pivotal role in the socio-economic development of Bhutan where water resource is abundantly available and therefore several hydropower plants are being planned and a few under construction. However, with the presence of several potentially dangerous glacier lakes within the higher elevations, the country is always at the risk of Glacial Lake Outburst Flood (GLOF) and climate change which poses higher uncertainty regarding the sustainability of hydropower reservoirs in the long run. To understand the hydrological response of the basin, where new hydropower plants are going to be installed soon, a complex semi-distributed hydrological model has been prepared for the Punatshangchu basin using RS MINERVE. After calibration and validation of the model, it is observed that the model reflects low relative volume bias $(-0.196-0.050)$ and high Nash efficiency $(0.540-0.990)$ which is an important aspect to be considered for any hydropower dam and its operational schemes. Such a model is a viable tool well adapted to an operational flood forecasting system and management. With the built-in scheme for hydropower, reservoir, planner, and turbines within RS Minerve, it could be used to understand the array of scenarios for planning and operations.
\end{abstract}

\section{Keywords—RS Minerve, hydrological model, hydropower operation, GSM, HBV, SOCONT.}

\section{INTRODUCTION}

\subsection{Bhutan's Hydropower situation}

Most of the running rivers in Bhutan are fed by the glaciers and snow from the upper Himalayas of Bhutan. The flow in these rivers is also partly sustained by the seasonal monsoon rainfall which mostly occurs during July, August and September [1]. The country heavily relies on its water resources for its economic and social development which is mainly driven by hydropower. Bhutan's economy is also dependent on agriculture with about $51.3 \%$ of people involved in agricultural activities [2]. According to [3], revenue contribution to Gross Domestic Product (GDP) from agricultural crop production and hydropower electricity was $10.64 \%$ and $13.2 \%$ respectively. Revenue generated from agriculture and hydropower plays a huge role in economic development and improving the livelihood of the people in Bhutan. Considering the importance of hydropower plants to economic development, Bhutan has significantly invested in construction of dams with the first major plant, Chukha Hydropower Project (CHP-360MW) completed in 1986. Since then, many other hydropower plants (Tala Hydropower Project-1020MW, Kurichu Hydropower Project- 60MW, Mangdechu Hydropower Project-720MW) have been completed. Currently the Punatshangchu-I (1200MW) and Punatshangchu-II (1020 MW) are under construction and are expected to commission by 2024 and 2022 respectively [4]. The Royal Government of Bhutan (RGoB) is also planning on installing a $2560 \mathrm{MW}$ Sunkosh hydropower plant in Punatshangchu chu basin[5]. However, RGoB's objective to harness $10,000 \mathrm{MW}$ of hydroelectric power by the year 2020 could not be materialized. Nevertheless, the RGoB now plans on achieving energy generation based on long-term national objectives rather than setting the energy generation target in a short term. As of 2019, the total installed capacity has reached 2326MW[6].

However, the construction of these hydropower dams per se possess a bigger challenge owing to geological instabilities associated and thereby leading to project delays and cost overruns. As of March 2019, Bhutan's external debt has reached USD 2.65 billion which is around $\mathrm{Nu} .183$ billion [7] of which hydropower alone accounts for $80 \%$ of external debt. Further, the country's external debt is projected to reach $\mathrm{Nu} .225$ billion by the end of June 2021 [8-9]. Such a drastic rise in external debt is mainly associated with the delays and cost overruns of the ongoing construction of hydropower plants in the country. Given such investment in hydropower through loans and foreign direct investments (FDIs), it is imperative to investigate the sustainability and hydropower plants operations subjected to changing climatic conditions. 


\section{Journal of Applied Engineering, Technology and Management (JAETM)}

\subsection{Climate Change and Hydrological models}

There are greater concerns regarding the availability of water resources in Bhutan because of the impact of climate change. Although Bhutan is a carbon-negative country, it is bearing the impact of climate change. The impact of climate change is already evident in the country with the formation of numerous glacial lakes [10-12] in the last decades leading to potential disasters driven by the Glacial Lake Outburst Flood (GLOF)[13-14]. As a consequence of warming in the Himalayas, the glaciers are diminishing at a pace of 30 to 60 meters per decade in Bhutan [15]. The melted glacier is constantly increasing the glacial lake volume thereby increasing the chances of GLOF threats.

Since the GLOF of 1994, RGoB has been putting in efforts to reduce further calamities with the help of national awareness campaigns and disaster management policies. The RGoB to some extent has been able to address the issues by artificially lowering the potentially dangerous lakes [16]. Nevertheless, Bhutan has to be prepared because the weather in the future is expected to become more variable and extreme. It is also found that the mean annual rainfall over Bhutan is likely to increase in the future considering the different climate projections using General Circulation Models (GCMs) [17]. Similarly, the Fifth Assessment Report (AR5) of the Intergovernmental Panel on Climate Change (IPCC), projects an increase in rainfall extremes in Southeast Asia during monsoon. It also states that more than $85 \%$ of Coupled Model Intercomparison Project (CMIP5) models projects an increase in the East Asian summer monsoons, while more than 95\% of models project an increase in extreme rainfall events and also projects an increase in Indian summer monsoon [18], which inadvertently causes increased rainfall in Bhutan. Therefore, considering the fragile climate system of the Himalayas, it is essential to simulate, within the hydrological model, the hydropower operations which are indeed strongly influenced by the climate variations. With the current study, a hydrological model is developed which could be later adopted to integrate the hydropower plants and simulate their functioning under the forecasted inflows. It can also be used to evaluate the impact of climate change on flow regimes and subsequently on the hydropower generation thereof. Although there are several hydrological models such as Soil Water Assessment Tools (SWAT) which models based on Hydrologic Response Units (HRUs), however SWAT requires extensive input data regarding land use and soil data which are not predominantly available. Therefore, in this study RS-MINERVE has been adopted to model the hydrologic response of the basin which do not require information regarding land use and soil parameters. Additionally, it also models based on elevation-band HRUs.

Several studies conducted in Switzerland have shown the applicability of RS Minerve model for hydrological studies along with hydropower generation [19-21]. RS Minerve has also been used in Koshi river basin in Nepal and to a glaciated basin in the Andes of Peru [22]. To understand the hydrological response and flood management in Wangchu basin in Bhutan, a preliminary hydrological study was also done using RS Minerve by Druk Green Power Corporation (DGPC) in collaboration with Swiss Federal Institute of Technology (EPFL). The model did not well reproduce the hydrological response of the area and this was attributed to the quality of the input rainfall data. RS Minerve model is presently used in Canton of Valais in Switzerland for real-time flood forecasting and management, facilitating automatic warnings and proposing reservoir operation measures to reduce the flood damage [20] and to enhance energy production. The model also offers versatility with hydraulic structures such as spillway, gates, diversion, junctions, turbines and pumps, making it increasingly used to understand hydropower planning and operation.

Therefore, the study aims to develop a semi-distributed hydrological model for the Punatshangchu basin using RS-Minerve to understand the hydrological response of the basin. Such a model shall enable the assessment of the impact of climate change on the hydrological regime of the basin under different climatic scenarios. It can also be used to understand the reservoir emptying and filling operations. 


\section{Journal of Applied Engineering, Technology and Management (JAETM)}

\subsection{Study Area}
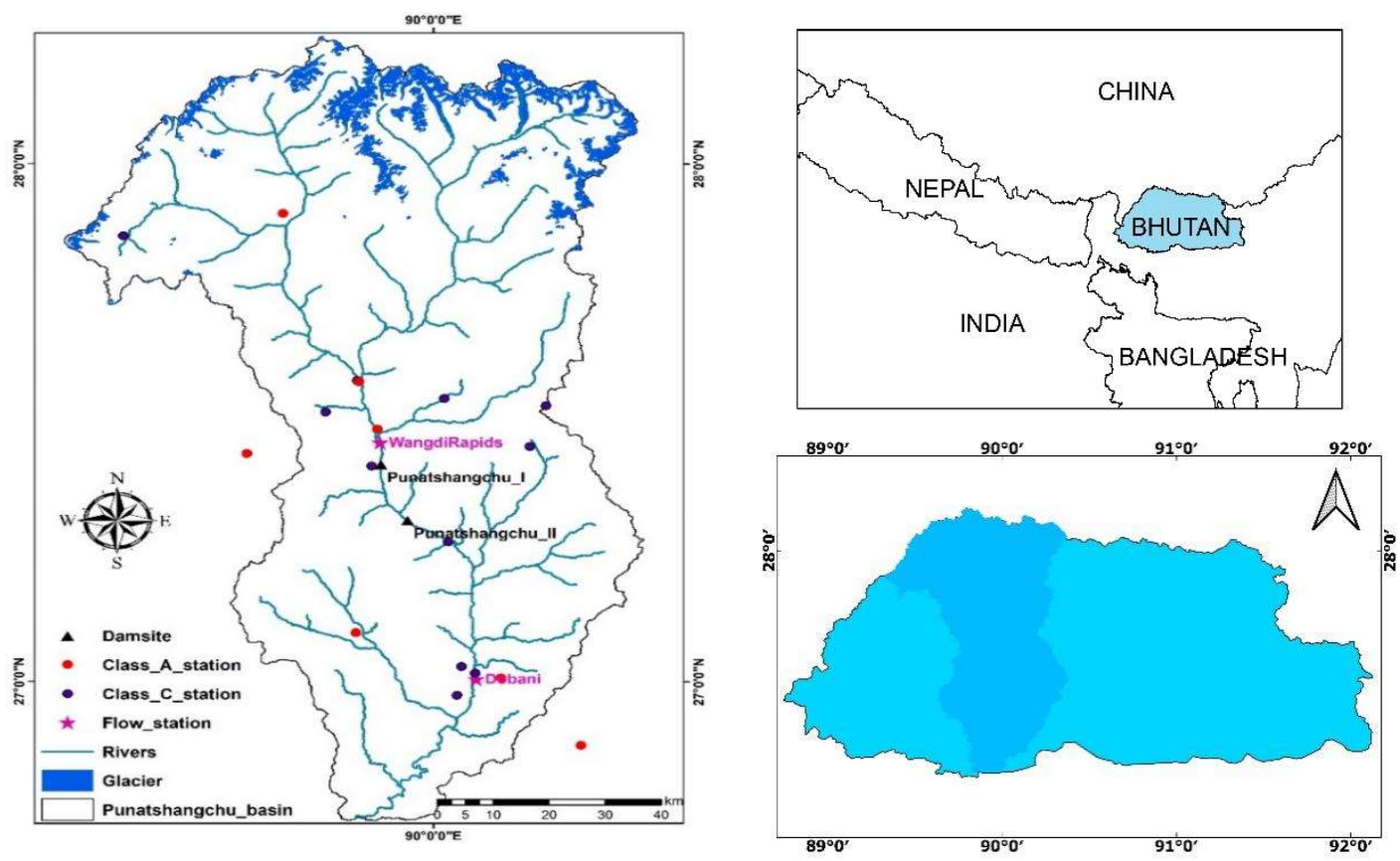

Fig. 1. Punatshangchu basin in Bhutan

Bhutan is nestled along the eastern Himalayan, located between China in the North and India in the South. The Punatshangchu basin covers the entire width of the country with an area of $9600 \mathrm{~km}^{2}$ and elevation ranging from $84 \mathrm{~m}$ to $7000 \mathrm{~m}$. The average rainfall in the southern part of the basin varies from 3000 to 5000 $\mathrm{mm} /$ year while the northern part receives 800 to $1500 \mathrm{~mm} / \mathrm{year}$. The minimum temperature in the south ranges from 12 to $15^{\circ} \mathrm{C}$ while the maximum temperature ranges from 28 to $32^{\circ} \mathrm{C}$. Similarly, the minimum temperature in the northern part ranges from -8 to $-0.5^{\circ} \mathrm{C}$ while the maximum temperature ranges from 10 to $16^{\circ} \mathrm{C}$.

Currently, the two hydropower dams under construction, Punatshangchu-I (1200 MW) and Punatshangchu-II (1020 MW) are expected to be done within 4 to 5 years. There are 18 meteorological stations covering the entire basin and two flow monitoring stations (Fig 1). The northern part of the basin is mostly covered by snow and glaciers. There are about 436 clean ice glaciers and 30 debris-covered glaciers [11] within the Punatshangchu basin covering a total area of $361.6 \pm 9.3 \mathrm{~km}^{2}$.

\section{DAtA}

The input data (Rainfall, temperature, and flow) for the hydrological model have been obtained from the National Centre of Hydrology and Meteorology (NCHM) in Bhutan. Rainfall and temperature data were considered from both the class-A and class-C meteorological stations. Class-A station is an agrometeorological station that measures temperature $(\min / \max )$, rainfall, humidity, soil temperature, wind speed/direction, sunshine hour, evaporation, and cloud cover, while the class-C station is a climatology station that only measures temperature $(\mathrm{min} / \mathrm{max})$, rainfall and humidity. The dataset contains missing values 


\section{Journal of Applied Engineering, Technology and Management (JAETM)}

and a selected period with fewer missing data has been used for modeling. The period between 2004-2007 (4 years) has been selected since it contains fewer missing values (Fig 2). Moreover, for the same period 2004-2007, the flow dataset was complete, with no missing values (Fig 3).

The missing data in the rainfall and temperature series for a particular day has been imputed using the mean values of that particular missing day from the whole historical data (1990-2017). Since the missing data ranged from a maximum of $12 \%$ for Tashithang and a minimum of $2 \%$ for Lingshi and Punakha, imputing with mean values is acceptable for the hydrological modeling.

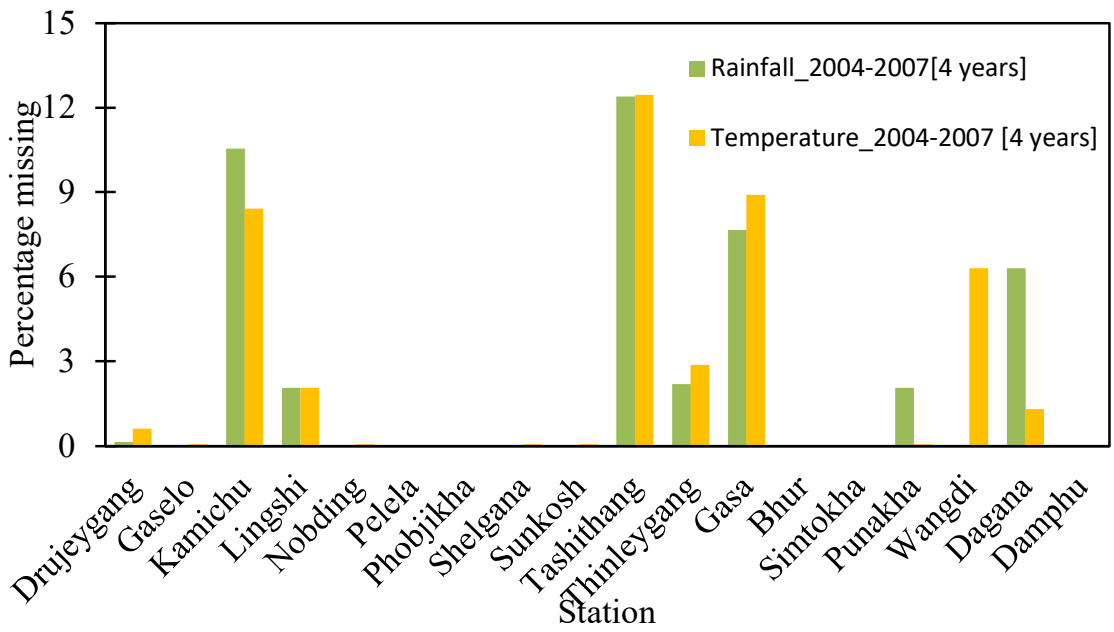

Fig. 2. Percentage of missing data in Rainfall and Temperature
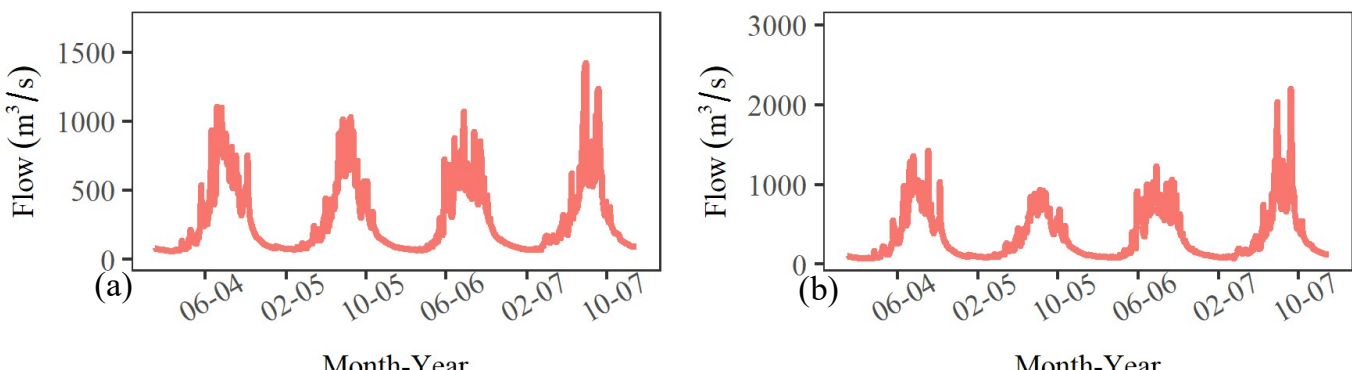

Fig. 3. Flow at (a) Wangdi Rapids (b) Dobani

Since the evapotranspiration data was not available for the studied area, it has been calculated through the RS Minerve software using the Turc's equation (1)

$$
E T P=\left\{\begin{array}{ll}
\text { CoeffETP.K. } \frac{T}{T+15} \cdot\left(R_{g}+50\right) & \text { if } T>0 \\
0 & \text { if } T \leq 0
\end{array}\right\}
$$




\section{Journal of Applied Engineering, Technology and Management (JAETM)}

Where $E T P=$ Evapotranspiration $(\mathrm{mm} / \mathrm{month}) ; \operatorname{CoeffETP}=1 ; T$ : air temperature $\left[{ }^{\circ} \mathrm{C}\right] ; R_{g}=$ global radiation $\left[\mathrm{cal} / \mathrm{cm}^{2} /\right.$ day]; $K=0.4$, if Month $\neq$ February and $K=0.37$, if Month $=$ February.

$R_{g}=$ monthly average of the global radiation $\left[\mathrm{kWh} / \mathrm{m}^{2} /\right.$ day], which is based on a location (latitude and longitude). It is obtained from (http://eosweb.larc.nasa.gov/sse) as a grid (latitude and longitude) and is consists of monthly averaged values.

\section{METHODS}

\subsection{Spatial discretization of Basin using TeResa software}

The Advanced Spaceborne Thermal Emission and Reflection Radiometer (ASTER) Digital Elevation Model (DEM) was downloaded from https://earthexplorer.usgs.gov/ which has been used to delineate subbasin using Quantum GIS (QGIS). For modeling, the entire study area was divided into 83 sub-basins with an average area of $115 \mathrm{~km}^{2}$ (Fig 4 a). The division was based on the location of confluence, flow stations, and dams. Besides sub-basin, glacier data and DEM were used to create an elevation band of $500 \mathrm{~m}$ using TeREsA software. It is an R-based program developed by the Centre de Recherche Sur l'Environnement Alpin (CREALP) to optimize environmental data analysis [23]. The TeREsA software discretized the basin into 592 elevation bands with 100 glaciated bands and 492 non-glaciated bands. Hydrological modeling is based on the 592-elevation band where each band behaves as a single hydrologic response unit (HRU). This allows in particular to account for the vertical evolution of temperature and influences the snow and ice melting processes.
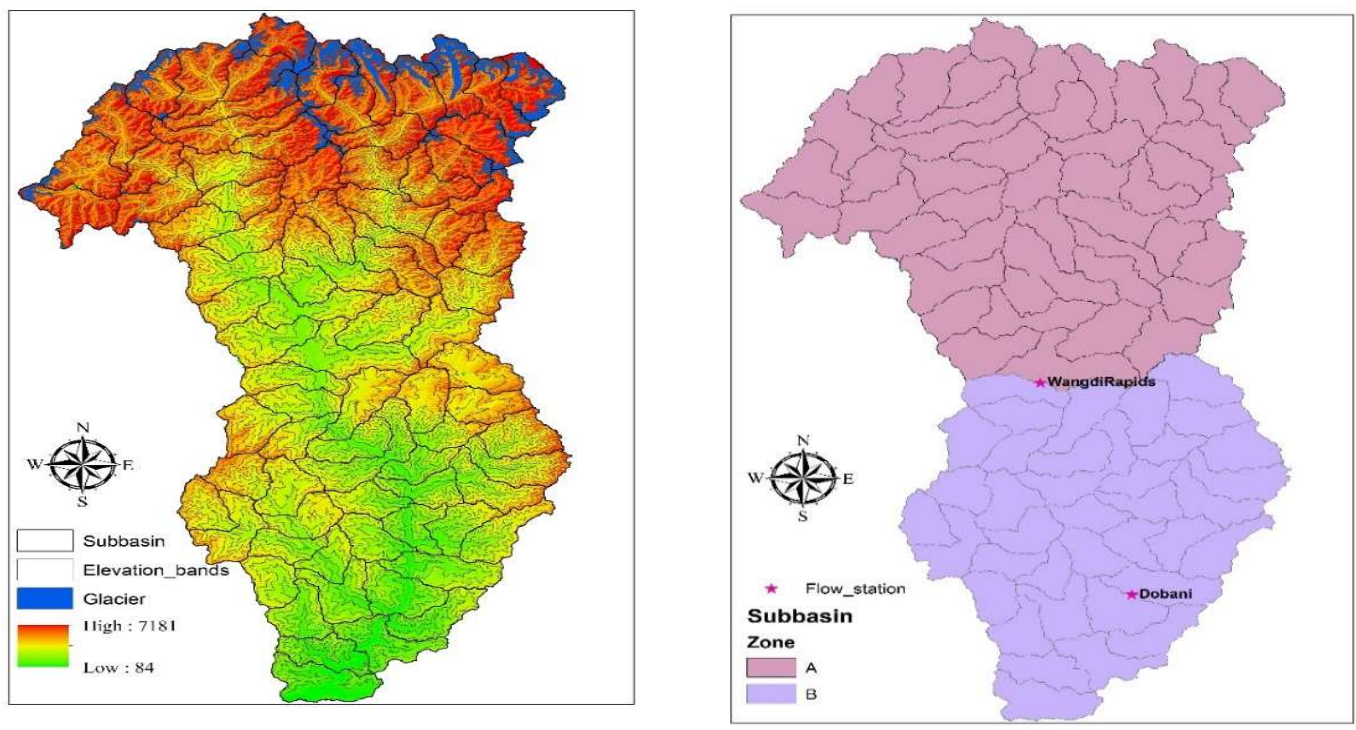

Fig. 4. (a) Discretization of the basin (b) Zoning of the Basin

The basin is further divided into two zones (Fig 4 b) based on the location of the flow stations. The subbasin above Wangdi Rapids flow station was grouped into Zone A and the rest of the sub-basin as Zone B. The zonation of sub-basin helps in the rigorous calibration of the model since it allows to proceed at the calibration in subsequent moments, therefore. 
Journal of Applied Engineering, Technology and Management (JAETM)

\subsection{Model construction using RS-MINERVE}

RS MINERVE is a tool jointly developed by the CREALP and the engineering office HydroCosmos SA, in collaboration with the Ecole Polytechnique Fédérale de Lausanne (EPFL) and Universitat Politècnica de València [24]. It is a semi-distributed hydrological-hydraulic tool used for the simulation of surface flow and propagation.

Based on the available model within the RS Minerve, GSM (Glacier Snow Melt), SOCONT (Soil CONTribution), and HBV (Hydrologiska ByrånsVattenbalansavdelning) model were chosen to understand the hydrological response of the basin. Since the Punatshangchu basin is a snow and glacier-fed basin, GSM was integrated with both the SOCONT and HBV models. The GSM model is assigned for glaciated subbasin while SOCONT and HBV are assigned for non-glaciated sub-basin. However, both the SOCONT and HBV take care of the snowmelt processes based on the inputs of rainfall and temperature.

The propagation of the flow was routed using the kinematic wave equation, where the model terms of local acceleration, convective acceleration, and pressure forces of the St. Venant's momentum equations are not considered. The one-dimensional mass conservation equation is given by (2) as:

$$
\frac{\partial Q}{\partial t}+\left(\frac{\partial Q}{\partial A}\right)_{x 0} \cdot \frac{\partial Q}{\partial x}=0
$$

This convection equation ensures the flow $\mathrm{Q}$ is propagated downstream with a celerity $c$ (3) which is defined as:

$$
c=\frac{\partial Q}{\partial A}
$$

Here, $A=$ Cross sectional area of river $\left(\mathrm{m}^{2}\right), t=$ time $(\operatorname{secs}), Q=$ flow $\left(\mathrm{m}^{3} / \mathrm{s}\right), x=\operatorname{distance}(\mathrm{m})$

\subsubsection{GSM-SOCONT Model}

The GSM model combines snow and glacier model while SOCONT combines snow, infiltration, and Runoff (SWMM) models [24]. Based on the inputs of temperature and rainfall, the snow model generates an equivalent rainfall which gets transported to the glacier model and then further down to linear snow reservoirs $\left(R_{s n}\right)$. Finally, it is moved to the outlet of the sub-basin. On the other hand, glacier flow is moved to the linear glacier reservoir $\left(R_{g l}\right)$ and then transferred to the outlet of the basin. The total flow $\left(Q_{t o t}\right)$ at sub-basin is based on the flow generated from both $R_{s n}$ and $R_{g l}$. Similarly, in the SOCONT model, based on temperature and rainfall, snow-SD model produces the equivalent rainfall which is moved to GR3 model. With the potential evapotranspiration (ETP), GR3 model delivers the net intensity (inet) to the Storm Water Management Model (SWMM) model [25].

\subsubsection{GSM-HBV Model}

The HBV model [26][27] is composed of a snow function, a humidity reservoir, and two (upper and lower) soil storage reservoirs. The model particularly takes care of interflow and baseflow.

\subsection{Performance Evaluation}

The Nash coefficient and Pearson Correlation coefficient are used to assessing the agreement between the observed and simulated flow. The Nash coefficient varies from $-\infty$ to 1 , with 1 representing the best performance of the model, while the latter varies from -1 to 1 , with 1 representing the best performance of the model. It is computed as: 


\section{Journal of Applied Engineering, Technology and Management (JAETM)}

$$
\begin{gathered}
\text { Nash }=1-\frac{\sum_{t=t_{i}}^{t_{f}}\left(X_{\text {sim }, t}-X_{r e f, t}\right)^{2}}{\sum_{t=t_{i}}^{t_{f}}\left(X_{r e f, t}-\bar{X}_{s i m, t}\right)^{2}} \\
\text { Pearson }=\frac{\sum_{t=t_{i}}^{t_{f}}\left(X_{s i m, t}-\bar{X}_{s i m}\right) \cdot\left(X_{r e f, t}-\bar{X}_{r e f}\right)}{\sqrt{\sum_{t=t_{i}}^{t_{f}}\left(X_{s i m, t}-\bar{X}_{s i m}\right)^{2} \cdot\left(X_{r e f, t}-\bar{X}_{r e f}\right)^{2}}}
\end{gathered}
$$

The Relative Root Mean Square Error (RRMSE) is defined as the RMSE normalized to the mean of the observed values. The smaller the value of RRMSE, the better is the performance of the model.

$$
R R M S E=\frac{\sqrt{\frac{\sum_{t=t_{i}}^{t_{f}}\left(X_{\text {sim }, t}-X_{r e f, t}\right)^{2}}{n}}}{\bar{X}_{r e f}}
$$

The Relative Volume Bias (RVB), assesses the relative error associated with volumes between the simulated and the observed flow. The $R V B$ ranges from -1 to $+\infty$, with near-zero values indicates good model performance. Positive values indicate that the simulated variable produces a larger volume than the observed variable and vice-versa. It is computed as:

$$
R V B=\frac{\sum_{t=t_{i}}^{t_{f}}\left(X_{s i m, t}-X_{r e f, t}\right)}{\sum_{t=t_{i}}^{t_{f}}\left(X_{r e f, t}\right)}
$$

Where, $X_{\text {sim }}=$ Simulated flow, $X_{\text {ref }}=$ Observed flow, $\bar{X}_{\text {sim }}=$ Mean Simulated flow, $\bar{X}_{\text {ref }}=$ Mean observed flow

Normalise Peak Error (NPE) was used to assess the relative error associated with maximum or peak values between the simulated and observed values. It is computed as:

$$
N P E=\frac{S_{\max }-R_{\max }}{R_{\max }}
$$

Where, $S_{\max }=$ Maximum Simulated flow for the studied period,

$R_{\max }=$ Maximum observed flow for the studied period 


\section{Journal of Applied Engineering, Technology and Management (JAETM)}

\section{RESULTS}

The hydrological model is calibrated over two years 2004-2005 and validated over 2006-2007. The calibration has been done zone by zone as previously described. The initial condition has been determined by considering the results of a first run of the model. The calibration is based on the historical data of precipitation, temperature, and discharge. The automatic calibration module of the RS Minerve has been used, which uses a single objective function composed of several performance indicators as shown in Table 1 and Table 2 .

TABLE 1. Performance indicator for flow during calibration (2004-2005)

\begin{tabular}{lllll}
\hline \multirow{2}{*}{ Performance Indicator } & \multicolumn{2}{l}{ GSM-SOCONT } & \multicolumn{3}{l}{ GSM-HBV } \\
\cline { 2 - 5 } & Wangdi_rapids & Dobani & Wangdi_rapids & Dobani \\
\hline Nash & 0.799 & 0.831 & 0.703 & 0.990 \\
Pearson Corr. Coef. & 0.943 & 0.942 & 0.911 & 0.894 \\
Relative Volume Bias & -0.015 & -0.032 & -0.047 & -0.090 \\
RRMSE & 0.392 & 0.347 & 0.480 & 0.495 \\
Normalised Peak error & 0.131 & -0.081 & 0.307 & 0.122 \\
\hline
\end{tabular}

TABLE 2. Performance indicator for flow during validation (2006-2007)

\begin{tabular}{lllll}
\hline \multirow{2}{*}{ Performance Indicator } & \multicolumn{2}{l}{ GSM-SOCONT } & \multicolumn{3}{l}{ GSM-HBV } \\
\cline { 2 - 5 } & Wangdi_rapids & Dobani & Wangdi_rapids & Dobani \\
\hline Nash & 0.535 & 0.744 & 0.653 & 0.756 \\
Pearson Corr. Coef. & 0.849 & 0.876 & 0.828 & 0.895 \\
Relative Volume Bias & 0.050 & -0.059 & -0.093 & -0.196 \\
RRMSE & 0.614 & 0.470 & 0.533 & 0.468 \\
Normalised Peak error & 0.542 & 0.071 & -0.232 & -0.358 \\
\hline
\end{tabular}

\subsection{Flow from GSM-SOCONT model}
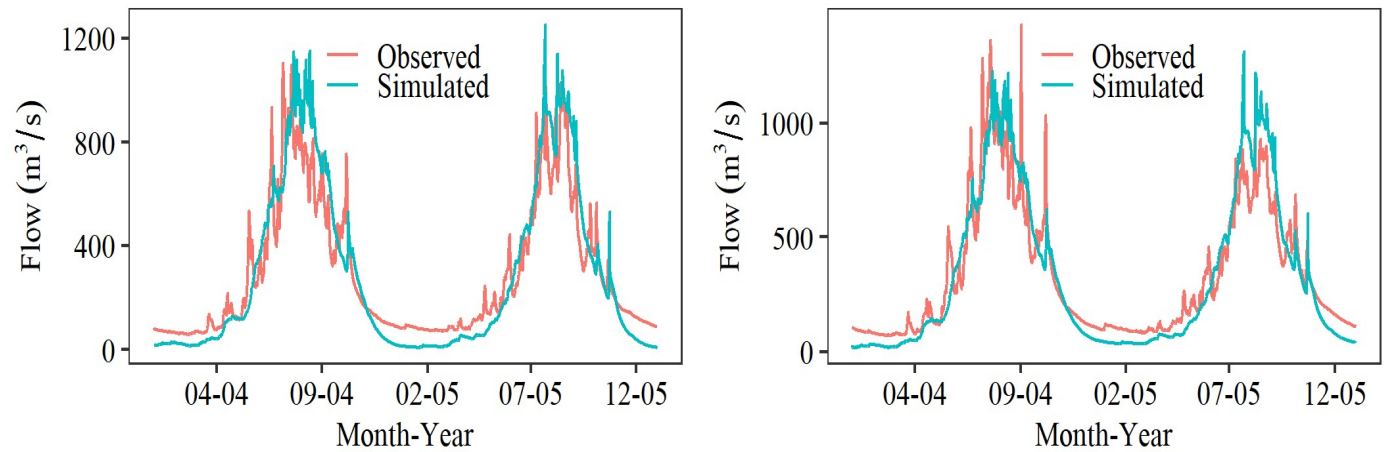

Fig. 5. Calibration plot (a) Wangdi rapids (b) Dobani for GSM-SOCONT 


\section{Journal of Applied Engineering, Technology and Management (JAETM)}
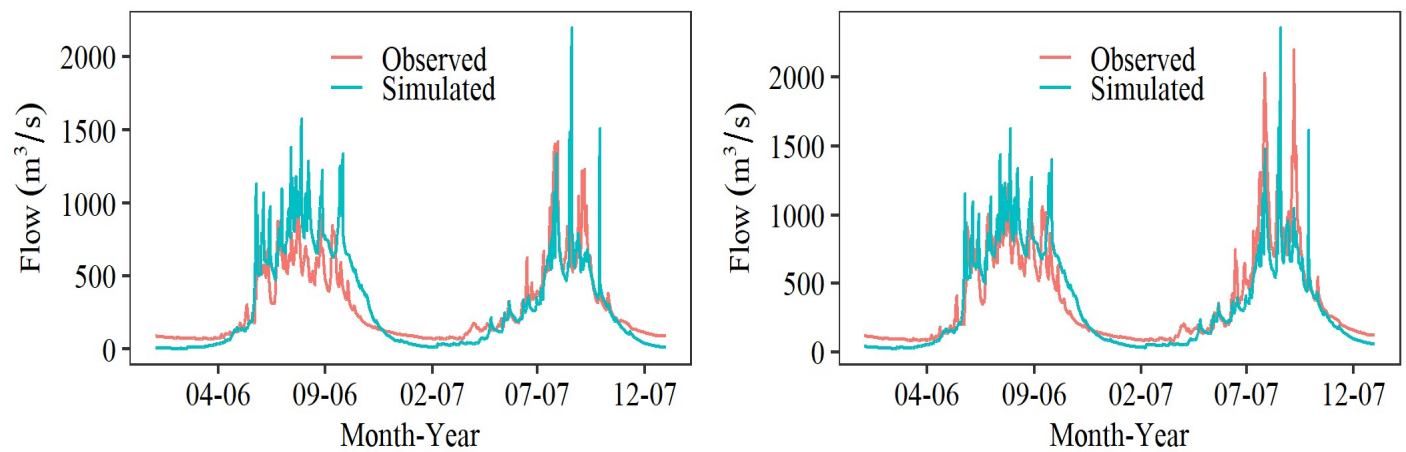

Fig. 6. Validation plot (a) Wangdi rapids (b) Dobani for GSM-SOCONT

GSM-SOCONT model was simulated on an hourly time step and from the above result, it is observed that GSM-SOCONT performs well for the peaks but it under-simulates the low flow condition (Fig 5 and Fig 6). Nevertheless, the model result is acceptable for both the calibration and validation phases. The parameters adopted for calibration are shown in Table 3.

TABLE 3. Model Parameters of GSM-SOCONT model

\begin{tabular}{|c|c|c|c|c|c|c|}
\hline \multirow{2}{*}{$\begin{array}{l}\text { Model } \\
\text { GSM- } \\
\text { SOCONT }\end{array}$} & \multirow[t]{2}{*}{ Name } & \multirow[t]{2}{*}{ Unit } & \multirow[t]{2}{*}{ Description } & \multirow[t]{2}{*}{$\begin{array}{l}\text { Regular } \\
\text { Range }\end{array}$} & \multicolumn{2}{|c|}{$\begin{array}{l}\text { Calibrated } \\
\text { parameter }\end{array}$} \\
\hline & & & & & $\begin{array}{l}\text { Zone } \\
\text { A }\end{array}$ & Zone B \\
\hline \multirow{6}{*}{ GSM } & G & $\begin{array}{l}\mathrm{mm} /{ }^{\circ} \mathrm{C} / \\
\mathrm{d}\end{array}$ & Degree-day ice melt coeff. & $0.5-20$ & 19.885 & \\
\hline & Gint & $\begin{array}{l}\mathrm{mm} /{ }^{\circ} \mathrm{C} / \\
\mathrm{d}\end{array}$ & Degree-day glacier melt interval & $0-4$ & 3.320 & \\
\hline & $\mathrm{S}$ & $\begin{array}{l}\mathrm{mm} /{ }^{\circ} \mathrm{C} / \\
\mathrm{d}\end{array}$ & $\begin{array}{l}\text { Reference degree-day snowmelt } \\
\text { coeff. }\end{array}$ & $0.5-20$ & 0.572 & \\
\hline & Sint & $\begin{array}{l}\mathrm{mm} /{ }^{\circ} \mathrm{C} / \\
\mathrm{d}\end{array}$ & Degree-day snowmelt interval & $0-4$ & 0.031 & \\
\hline & $\mathrm{Kgl}$ & $1 / \mathrm{d}$ & Release coeff. of icemelt reservoir & $0.1-5$ & 0.315 & \\
\hline & Ksn & $1 / \mathrm{d}$ & $\begin{array}{l}\text { Release coeff. of snowmelt } \\
\text { reservoir }\end{array}$ & $0.1-5$ & 0.494 & \\
\hline \multirow{5}{*}{ SOCONT } & $\mathrm{S}$ & $\begin{array}{l}\mathrm{mm} /{ }^{\circ} \mathrm{C} / \\
\mathrm{d}\end{array}$ & $\begin{array}{l}\text { Reference degree-day snow melt } \\
\text { coeff. }\end{array}$ & $0.5-20$ & 1.667 & 19.547 \\
\hline & Sint & $\begin{array}{l}\mathrm{mm} /{ }^{\circ} \mathrm{C} / \\
\mathrm{d}\end{array}$ & Degree-day snowmelt interval & $0-4$ & 0.538 & 0.492 \\
\hline & $\begin{array}{l}\text { HGR3Ma } \\
\mathrm{x}\end{array}$ & $\mathrm{m}$ & $\begin{array}{l}\text { Maximum height of infiltration } \\
\text { reservoir }\end{array}$ & $0-2$ & 1.598 & 1.897 \\
\hline & KGR3 & $1 / \mathrm{s}$ & $\begin{array}{l}\text { Release coeff. of infiltration } \\
\text { reservoir }\end{array}$ & $\begin{array}{l}0.00025- \\
0.1\end{array}$ & 0.002 & $\begin{array}{l}0.0002 \\
5\end{array}$ \\
\hline & $\mathrm{Kr}$ & $\mathrm{m}^{1 / 3} / \mathrm{s}$ & Strickler coefficient & $0.1-90$ & 1.201 & 2 \\
\hline
\end{tabular}




\section{Journal of Applied Engineering, Technology and Management (JAETM)}

\subsection{Flow from GSM-HBV model}
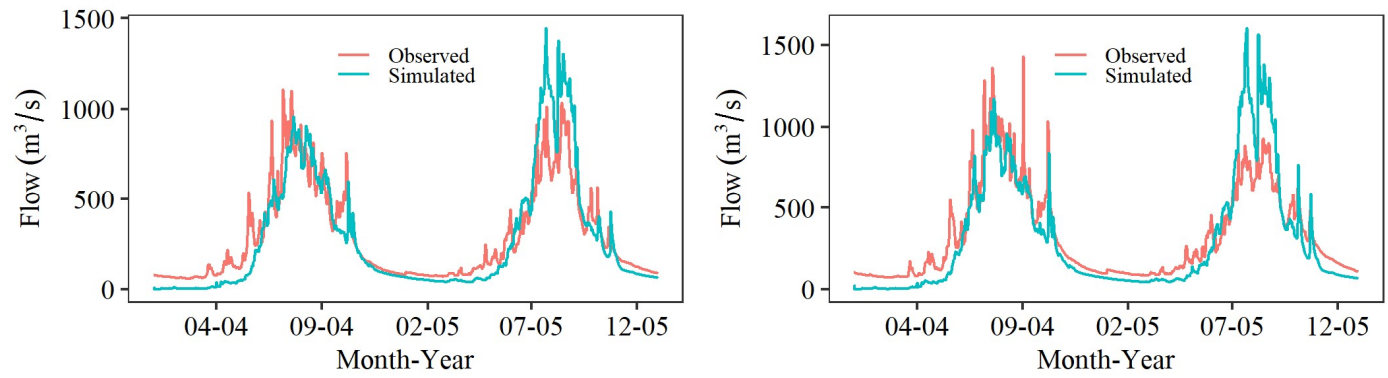

Fig. 7. Calibration plot (a) Wangdi rapids (b) Dobani for GSM-HBV
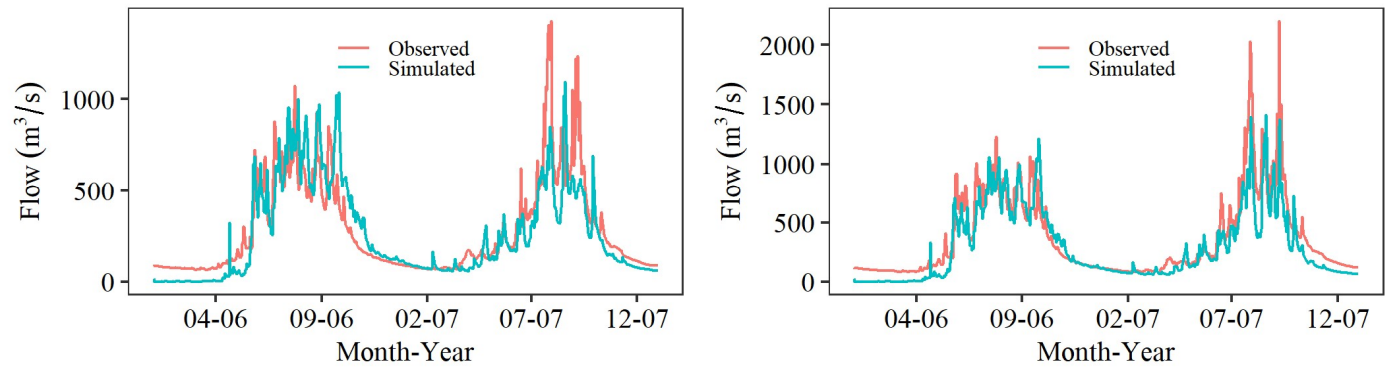

Fig. 8. Validation plots (a) Wangdi rapids (b) Dobani for GSM-HBV

On the other hand, GSM-HBV model was simulated on a daily time step and it is observed that the model performs better for low flow conditions (Fig 7 and Fig 8), however, the peaks are not very well represented. Nevertheless, both the GSM-SOCONT and GSM-HBV model reflects low relative volume bias and high Nash efficiency (Table1 and Table 2), which is an important aspect to be considered for any hydropower dam and its operational schemes. Table 4 shows the model parameter that was adopted for calibration.

TABLE 3. Model parameters of GSM-HBV model

\begin{tabular}{|c|c|c|c|c|c|c|}
\hline \multirow{2}{*}{$\begin{array}{l}\text { Model } \\
\text { GSM- } \\
\text { HBV }\end{array}$} & \multirow[t]{2}{*}{ Name } & \multirow[t]{2}{*}{ Unit } & \multirow[t]{2}{*}{ Description } & \multirow[t]{2}{*}{$\begin{array}{l}\text { Regular } \\
\text { Range }\end{array}$} & \multicolumn{2}{|c|}{$\begin{array}{l}\text { Calibrated } \\
\text { parameter }\end{array}$} \\
\hline & & & & & $\begin{array}{l}\text { Zone } \\
\text { A }\end{array}$ & $\begin{array}{l}\text { Zone } \\
\text { B }\end{array}$ \\
\hline \multirow{6}{*}{ GSM } & G & $\begin{array}{l}\mathrm{mm} /{ }^{\circ} \mathrm{C} / \\
\mathrm{d}\end{array}$ & Degree-day ice melt coeff. & $0.5-20$ & 19.885 & \\
\hline & Gint & $\begin{array}{l}\mathrm{mm} /{ }^{\circ} \mathrm{C} / \\
\mathrm{d}\end{array}$ & Degree-day glacier melt interval & $0-4$ & 3.320 & \\
\hline & $\mathrm{S}$ & $\begin{array}{l}\mathrm{mm} /{ }^{\circ} \mathrm{C} / \\
\mathrm{d}\end{array}$ & $\begin{array}{l}\text { Reference degree-day snowmelt } \\
\text { coeff. }\end{array}$ & $0.5-20$ & 14.500 & \\
\hline & Sint & $\begin{array}{l}\mathrm{mm} /{ }^{\circ} \mathrm{C} / \\
\mathrm{d}\end{array}$ & Degree-day snowmelt interval & $0-4$ & 0.691 & \\
\hline & $\mathrm{Kgl}$ & $1 / \mathrm{d}$ & Release coeff. of icemelt reservoir & $0.1-5$ & 0.315 & \\
\hline & Ksn & $1 / \mathrm{d}$ & Release coeff. of snowmelt reservoir & $0.1-5$ & 0.494 & \\
\hline
\end{tabular}


Journal of Applied Engineering, Technology and Management (JAETM)

\begin{tabular}{|l|l|l|l|l|l|l|}
\hline & PWP & - & $\begin{array}{l}\text { Soil permanent wilting point } \\
\text { threshold }\end{array}$ & 0.03 to 1 & 0.999 & 0.999 \\
\cline { 2 - 8 } & $\begin{array}{l}\text { SUMa } \\
\mathrm{x}\end{array}$ & $\mathrm{m}$ & $\begin{array}{l}\text { Upper reservoir water level } \\
\text { threshold }\end{array}$ & 0 to 0.10 & 0.099 & 0.027 \\
\cline { 2 - 9 } & $\mathrm{Kr}$ & $1 / \mathrm{d}$ & Near-surface flow storage coeff. & $\begin{array}{l}0.05 \text { to } \\
0.5\end{array}$ & 0.050 & 0.427 \\
\cline { 2 - 9 } & $\mathrm{Ku}$ & $1 / \mathrm{d}$ & Interflow storage coeff. & $\begin{array}{l}0.01 \text { to } \\
0.4\end{array}$ & 0.145 & 0.399 \\
\cline { 2 - 9 } & $\mathrm{Kl}$ & $1 / \mathrm{d}$ & Baseflow storage coeff. & 0 to 0.15 & 0.010 & 0.013 \\
\cline { 2 - 9 } & $\mathrm{Kperc}$ & $1 / \mathrm{d}$ & Percolation storage coeff. & 0 to 0.8 & 0.089 & 0.06 \\
\hline
\end{tabular}

\section{CONCLUSION AND DISCUSSION}

Climate change possess a negative impact especially along Himalayan region which are considered to be a water towers of Asia. With the glaciers and snow receding at unprecedented rate, availability of water for drinking and hydropower generation seems uncertain. Investing in hydropower, results in huge revenue generation which could be used for socio-economic development of a country. However, there is higher uncertainty of the sustenance of hydropower with changing climate. Basins in Bhutan is expected receive GLOF threats with increase in rainfall and temperature in Bhutan.

With the two mega-hydropower plants in the Punatshangchu basin under construction, such threats necessitate having proper hydropower operation plans which could provide useful information in emptying and filling operation of the dams. Without such a plan it inadvertently causes huge damages to the properties, livelihood, and economy of the country as a whole. One such plan could be made possible using a hydrological model which could simulate the hydrological response of the basin. The current study works on the development of a semi-distributed hydrological model in the Punatshangchu basin in Bhutan using RS Minerve. Two models, GSM-SOCONT and GSM-HBV, available within RS Minerve, were selected for simulating the flow at two flow gauging stations. The missing data in the rainfall and temperature were imputed using mean values from the historical data since the missing data only ranged from $2 \%$ to $12 \%$ which is generally accepted for hydrological models. Based on the input data as above, the hydrological model was developed for the basin with different elevation band which behaves as a single HRUs. Those HRUs located in the glaciated zones were modelled using the GSM model while the rest of the non-glaciated HRUs was modelled using SOCONT and HBV model.

The model has been calibrated and validated and it well simulates the flow in the basin. From both the models, it is observed that the model reflects low relative volume bias $(-0.196-0.050)$ and high Nash efficiency $(0.540-0.990)$ which is an important aspect to be considered for any hydropower dam and its operational schemes. The model could be improved further with field-based evapotranspiration data. Besides modelling hydrological processes, RS Minerve is also capable of modelling hydraulic control elements like gates, spillways, diversions, junctions, turbines, and pumps which can be used to understand the operational schemes of the dam and power generation thereof.

\section{ACKNOWLEDGEMENTS}

The study acknowledges the support of the Swiss State Secretariat for Education, Research and Innovation (SERI) and ZHAW Zurich University of Applied Sciences which facilitated the mobility of South Asian researchers to Switzerland with the mobility grant. The study also acknowledges the Platform of Hydraulic Construction, Swiss Federal Institute of Technology, Lausanne (EPFL) for the support of the research. 
Journal of Applied Engineering, Technology and Management (JAETM)

\section{REFERENCES}

[1] V. Sharma and K. Adhikari, "Rainfall and Rainy days trend and ENSO Phenomena in Himalayan Kingdom of Bhutan,” Int. J. Spat. Temporal Multimed. Inf. Syst., pp. 1-18, 2020, doi: 10.1504/IJSTMIS.2020.10035484.

[2] MOLHR, "Labour Force Report Survey," Ministry of Labour and Human Resource,Thimphu, 2017.

[3] National Statistics Bureau, "National Accounts Statistics," Royal Government of Bhutan,Thimphu, 2018.

[4] T. Palden, "PHPA I's commission pushed to 2024," Kuenselonline, Thimphu, Feb. 18, 2019. [Online]. Available: http://www.kuenselonline.com/phpa-is-commission-pushed-to-2024/

[5] P. Tshewang, "Farmers are not allowed to plant permanent cash crops due to Sunkosh Hydropower Project, Dagana," BBS (Bhutan Broadcasting Service), Dagana, Jun. 23, 2021. [Online]. Available: http://www.bbs.bt/news/?p=143114

[6] RGoB, "Bhutan Sustainable Hydropower Development Policy,” Thimphu, Bhutan, 2020. [Online]. Available: https://www.gnhc.gov.bt/en/wp-content/uploads/2020/03/SHDP-Submittedto-GNHC-March-16-2020.pdf

[7] S. Dorji, "Bhutan's Debt to GDP ratio increased to 111\%," Bhutan Broadcasting Service, Thimphu, Jul. 22, 2019. [Online]. Available: http://www.bbs.bt/news/?p=117981

[8] T. Dorji, “External debt to hit 204B in 2018-2019," Kuensel, Thimphu, Jan. 14, 2019. [Online]. Available: http://www.kuenselonline.com/external-debt-to-hit-204b-in-2018-19/

[9] M. Subba, "External debt projected to increase to Nu 225B by end of June.," Kuensel, 2021. https://kuenselonline.com/external-debt-projected-to-increase-to-nu-225b-by-end-of-june/ (accessed Jun. 05, 2021).

[10] P. K. Mool, D. Wangda, S. R. Bajracharya, K. Kunzang, D. R. Gurung, and S. Joshi, "Inventory of Glaciers, Glacial Lakes and Glacial Lake Outburst Floods Monitoring and Early Warning Systems in the Hindu Kush-Himalayan Region Bhutan," International Centre for Integrated Mountain Development, Kathmandu, 2001.

[11] S. R. Bajracharya, S. B. Maharjan, and F. Shrestha, "The status and decadal change of glaciers in Bhutan from the 1980 s to 2010 based on satellite data," Ann. Glaciol., vol. 55, no. 66, pp. 159166, 2014, doi: 10.3189/2014AoG66A125.

[12] S. K. Jain, R. K. Sinha, A. Chaudhary, and S. Shukla, "Expansion of a glacial lake, Tsho Chubda, Chamkhar Chu Basin, Hindukush Himalaya, Bhutan," Nat Hazards, vol. 75, pp. 1451-1464, 2015, doi: 10.1007/s11069-014-1377-z.

[13] N. Wangdi and K. Kusters, "The costs of adaptation in Punakha, Bhutan : Loss and damage associated with changing monsoon patterns," 2012.

[14] D. R. Gurung, N. R. Khanal, S. R. Bajracharya, K. Tsering, S. Joshi, P. Tshering, L. . Chhetri, et al., "Lemthang Tsho glacial Lake outburst flood ( GLOF ) in Bhutan : cause and impact," Geoenvironmental Disasters, vol. 4, no. 17, pp. 1-13, 2017, doi: 10.1186/s40677-017-0080-2.

[15] UNDP, "Reducing Climate Change-induced Risks and Vulnerabilities from Glacial Lake Outburst Floods in the Punakha-Wangdi and Chamkhar Valley.," Thimphu, Bhutan, 2007.

[16] WWF, "The Cost of Climate Change: The Story of Thorthormi Glacial Lake in Bhutan," 2009. 
Journal of Applied Engineering, Technology and Management (JAETM)

[Online].Available:

https://wwf.fi/app/uploads/h/5/7/5rqxrm5d15ejasicpp5m4zc/the_cost_of_climate_change.pdf

[17] NCHM, “Analysis of Historical Climate and Climate Projection for Bhutan," Royal Government of Bhutan, Thimphu, Bhutan, 2019.

[18] Y. Hijioka, E. Lin, J. J. Pereira, R. T. Corlett, X. Cui, G. E. Insarov, R. D. Lasco, et al., “Asia In: Climate Change 2014: Impacts, Adaptation, and Vulnerability. Part B: Regional Aspects.

Contribution of Working Group II to the Fifth Assessment Report of the Intergovernmental Panel on Climate Change [Barros, V.R., C.B. Field, D.J. Dokken, M.D. M," Cambridge University Press, Cambridge, United Kingdom and New York, NY, USA, 2014.

[19] J. G. Hernández, F. Jordan, and A. Schleiss, "Ensemble hydrological forecasts for the Upper Rhone River basin," in 33rd IAHR Congress: Water Engineering for a Sustainable Environment, 2009, pp. 1171-1178.

[20] J. G. Hernández, A. Claude, J. P. Arquiola, B. Roquier, and J. . Boillat, "Integrated flood forecasting and management system in a complex catchment area in the Alps — implementation of the MINERVE project in the Canton of Valais," in Swiss Competences in River Engineering and Restoration, 2014, pp. 87-98.

[21] M. Ponce, J. Zordan, P. Manso, and C. Münch, "Added value of smart storage operations on an alpine run-off-river HPP obtain from hydrological-hydraulic modelling," 2019. doi: 10.3189/2014JoG14J011.

[22] F. Drenkhan, C. Huggel, J. G. Hernández, J. F. Sanmartin, J. Seidel, and R. Munoz, “An integrative water balance model framework for a changing glaciated catchment in the Andes of Peru," in 2017EGUGA..19.5818D, 2017, p. 5818.

[23] J. F. Sanmartin, A. Foehn, E. Travaglini, S. Alesina, R. Montero-Rubert, and J. G. Hernandez, “TeREsA -Technical Manual v1.1," CREALP Group, Switzerland, 2016.

[24] A. Foehn, J. G. Hernandez, B. Roquier, J. F. Sanmartin, J. P. Arquiola, and G. De Cesare, "RS MINERVE v2.14 - User Manual," CREALP, Switzerland. ISSN 2673-2653, 2019.

[25] J. G. Hernandez, A. Foehn, J. F. Sanmartin, B. Roquier, J. P. Arquiola, and G. De Cesare, "RS MINERVE - Technical Manual v2.23,” 2019. [Online]. Available: http://rsminerve.hydro10.org/

[26] S. Bergström, "Development and Application of a Conceptual Runoff Model for Scandinavian Catchments," Swedish Meteorological and Hydrological Institute, 1976. doi: 10.1007/s11069004-8891-3.

[27] S. Bergström, "The HBV model - its structure and applications," Swedish Meteorological and Hydrological Institute, Norrköping, 1992. 